\title{
Noch individuellere Arbeit mit den Artikulatoren ermo̊glicht
}

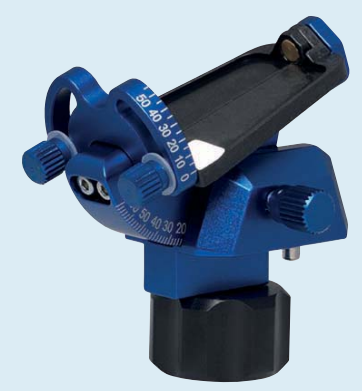

Der Name Stratos steht für Präzisions-Artikulatoren. Ivoclar Vivadent bietet hier ein exakt auf die Kundenbedürfnisse abgestimmtes Gerätesortiment. Nun ermöglicht neues Zubehör noch individuellere Arbeiten. Mit dem neu erhältlichen individuellen Frontzahnführungsteller und dem dazu massgeschneiderten gebogenen Inzisalstift steht Anwendern ab sofort das ideale Zubehör zum individuell einstellbaren Artikulator Stratos 300 zur Verfügung. Darüber hinaus sind beide Produkte aber auch für alle übrigen Artikulatoren der Marke Stratos verwendbar. Der individuelle Frontzahnführungsteller ermöglicht die individuelle Einstellung der Winkelwerte für den Frontzahnbereich. Der laterale Front- zahnführungswinkel kann zwischen 0 und $70^{\circ}$ stufenlos eingestellt werden. Klemmschrauben ermöglichen eine gute, stabile Fixierung der Bewegungselemente. Die Metalloberfläche ist hochwertig und eloxiert. Der gebogene Inzisalstift wird für den individuellen Frontzahnführungsteller benötigt, er ermöglicht ein exaktes, stufenloses Anheben und Absenken der Artikulatorhöhe. Die Anzeige erfolgt mit einer Millimeterskala. Sie macht die Restauration viel passgenauer und individueller. Mittels Justierbolzen lässt sich das gesamte System genau aufeinander ausrichten. Ein weiterer Vorteil liegt in der nachträglichen Justierungsmöglichkeit direkt vor Ort.

Nach einer Pressemitteilung der Ivoclar Vivadent $\mathbf{G m b H}$,

Ellwangen (Jagst)

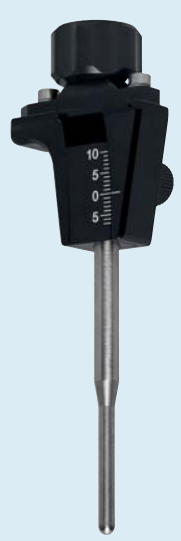

